\title{
O PC DO B E O MOVIMENTO COMUNISTA INTERNACIONAL NOS ANOS 60*
}

\author{
Jean Rodrigues Sales**
}

\begin{abstract}
RESUMO
Este artigo pretende discutir as relações políticas e ideológicas do PC do B com o chamado movimento comunista internacional na década de 60. Mais especificamente com a URSS, com Cuba e com a China.

Palavras-chave: PC do B, movimento comunista internacional, anos 60.

ABSTRACT

This article aims to discuss the political and ideological relation between the Communist Party of Brazil and the international communist movement in the sixties, more specifically its relations to USSR, Cuba and China.
\end{abstract}

Key-words: Communist Party of Brazil, international communist movement, the 60's.

\section{Introdução}

Discutir as relações do Partido Comunista do Brasil (PC do B) com o movimento comunista internacional implica em lidar com um problema teórico que não está resolvido na bibliografia sobre o assunto. Tal

* Este texto é uma versão resumida de um capítulo de minha dissertação de mestrado, defendida na Unicamp, com o apoio da Fapesp. Partes dele foram apresentadas em dois congressos: na XVIII Semana de História de Assis - realizada entre 29/05 e 2/06 de 2000 - e no XV Encontro Regional de História (ANPUH) - realizado na Universidade de São Paulo entre 4 e 8 de setembro de 2000.

** Doutorando em História no IFCH - Unicamp. E-mail: jeanrodrigues@bol.com.br 
questão diz respeito justamente ao caráter e às implicações desse relacionamento para o partido. Em outras palavras, em que medida a filiação de determinado agrupamento político a um centro revolucionário - basicamente a URSS, Cuba ou China - influencia as suas concepções teóricas e a sua prática política? Até que ponto a vida dos partidos comunistas é afetada pelas divergências no comunismo internacional?

Podemos dizer que há, no que diz respeito às relações das esquerdas brasileiras com o comunismo internacional, pelo menos duas proposições teóricas para o entendimento de nossa questão. Uma, ainda que nem sempre explicitada claramente nos trabalhos, vê a relação com os centros revolucionários como elemento fundamental para o entendimento das definições ideológicas e da atuação política dos grupos nacionais, e, dessa forma, como fator decisivo para o entendimento da história desses agrupamentos. Em seu extremo, essa interpretação vê a atuação dos grupos comunistas como sendo determinada pelos centros revolucionários, quase como se aqueles funcionassem como satélites destes. ${ }^{1}$

Uma segunda abordagem foi proposta em um trabalho importante sobre as esquerdas comunistas brasileiras na década de sessenta. Para o autor, Daniel Aarão Reis Filho, ${ }^{2}$ seria corrente, na bibliografia especializada, a interpretação de que a relação das organizações comunistas brasileiras com os centros revolucionários seria de submissão à política neles traçada, de onde viriam as causas das várias derrotas sofridas pelas esquerdas. Ao traçar suas políticas através de ecos de diretrizes internacionais, os comunistas brasileiros não conseguiriam entender e atuar na sua própria realidade, levando-os assim a cometerem erros na elaboração e na aplicação de seus programas.

1 Nessa linha estão muitos trabalhos sobre a história do $\mathrm{PCB}$, entre os quais podemos citar: CARONE, E. O PCB - 1922-1982. Rio de Janeiro: Bertrand, 1973. 3 v.; PACHECO, E. O Partido Comunista do Brasil, 1922-1964. São Paulo: Alfa-Ômega, 1984; SANTOS, R. A primeira renovação pecebista: reflexos do XX Congresso do PCUS no PCB. Belo Horizonte: Oficina de Livros, 1988. O extremo dessa interpretação pode ser vista no trabalho de VINHAS, M. O partidão: a luta por um partido de massas, 19221944. Rio de Janeiro: Graal, 1982; e no de CHILCOTE, R. O Partido Comunista Brasileiro: conflito e integração, 1922-1972. Rio de Janeiro: Graal, 1982.

2 REIS FILHO, D. A. A revolução faltou ao encontro. Os comunistas no Brasil. 2. ed. São Paulo: Brasiliense, 1990. Fizemos uma discussão mais detida sobre a proposição analítica de Reis Filho em nossa dissertação de mestrado, ver: SALES, J. R. Partido Comunista do Brasil - PC do B: propostas teóricas e prática política (1962-1974). Campinas, 2000. Dissertação (Mestrado) - Universidade de Campinas. 
Diferentemente dessa interpretação, Reis Filho defende que as organizações comunistas não aderiam a um modelo, o que poderia ser demonstrado pelo fato de geralmente invocarem ao mesmo tempo as três experiências revolucionárias e também de tratarem com extrema prudência as cisões dentro do comunismo internacional. Segundo o autor, na verdade, essa relação serviria para dar "coesão, segurança e legitimidade" aos agrupamentos comunistas nacionais, que recorriam aos exemplos das revoluções vitoriosas para respaldarem as suas opções políticas.

Parece-nos que a tese do autor se justifica plenamente frente a análises que subordinam a dinâmica das esquerdas nacionais às "ordens" vindas de fora, deixando de lado, ou inferiorizando, os aspectos nacionais e as contradições internas de tais organizações nas suas formulações teóricas e em sua prática política. Como bem disse Reis Filho, se de fato as organizações brasileiras agissem de acordo com ordens vindas do exterior, os historiadores teriam que procurar as fontes para sua pesquisa na URSS, na China ou em Cuba e não nos arquivos brasileiros. Porém, para além desse tipo de análise, que reduz a história das esquerdas comunistas a suas relações com os centros revolucionários internacionais, parece-nos que a hipótese do autor, ao colocar essa relação estritamente nos termos de coesão, segurança e legitimação, pode levar talvez, em sentido oposto ao da interpretação anterior, a desconsiderarmos todas as dimensões e implicações que podem assumir as relações dos agrupamentos comunistas entre si e com os centros revolucionários. Vale lembrar que lidar com tais relações implica em trabalharmos com uma tradição que talvez possamos chamar, na falta de um termo que dê conta do problema em toda sua temporalidade e intensidade, de "internacionalismo proletário" e que ultrapassa os limites da própria III IC, remetendo-nos a discussões no interior do movimento operário desde o século XIX. Um exemplo de análise que, a nosso ver, ultrapassa os limites propostos por Daniel Aarão pode ser vista no trabalho de Jorge Luiz Ferreira. O autor, partindo de referências teóricas propostas por Bronislaw Baczko, Raul Girardet e Pierre Ansart, discute a importância mítica e simbólica da URSS para os comunistas brasileiros e como esses aspectos simbólicos influenciaram a prática desses comunistas. ${ }^{3}$

3 Ferreira, J. L. Prisioneiros do mito: cultura e imaginário político dos comunistas no Brasil - 1930-1956. São Paulo, 1996. Tese (Doutorado) - Universidade de São Paulo. 
Um outro autor, Eric J. Hobsbawm, fez comentários interessantes a respeito das dificuldades na apreensão das relações estabelecidas entre os partidos comunistas e o Comitern, os quais também podem nos servir para demonstrar a complexidade do tema. Para ele, o que o historiador deve fazer é

...distinguir entre os elementos nacionais dos partidos comunistas e os internacionais, inclusive aquelas correntes dos movimentos nacionais que puseram em prática a linha internacional, não porque tivessem que fazê-lo, mas porque estavam realmente de acordo com ela. Devem distinguir entre os elementos genuinamente internacionais da política do Comitern e aqueles que refletiam apenas os interesses de Estado da URSS e as preocupações táticas ou de outra natureza da política interna soviética. Tanto no âmbito nacional quanto no internacional, devem distinguir entre as decisões políticas fundadas em conhecimento, ignorância ou intuição na análise marxista (correta ou não), tradição local, imitação de exemplos estrangeiros adequados ou não, ou pura tentativa e erro, percepção tática ou fórmulas ideológicas. Devem, acima de tudo, distinguir as políticas que alcançaram êxito e foram sensatas das que não foram, resistindo à tentação de condenar o Comitern en bloc como um fracasso ou um fantoche da Rússia. $^{4}$

Esta proposta de Hobsbawm, de distinguir os elementos nacionais dos internacionais na política dos partidos comunistas, não é tarefa fácil. Aldo Agosti teve que enfrentá-la ao discutir a relação dos grupos dirigentes dos partidos comunistas europeus com o Comitern. Para Agosti, essa relação seria marcada por uma "soberania limitada". A existência de tal limitação, porém, não deveria nos levar, segundo o autor,

...a conceber as relações entre o centro e as seções como um processo de mão única, ou os grupos dirigentes dos partidos nacionais como simples emanações do Comintern e meros

4 HOBSBAWM, E. J. Problemas da história do comunismo. In: HOBSBAWM, E. J. Revolucionários. Ensaios contemporâneos. Rio de Janeiro: Paz e Terra, 1982. p. 18. 
executores de suas ordens. Mesmo nos anos em que a intervenção do Executivo em sua formação foi mais direta, a alternância de diferentes grupos dirigentes na liderança dos partidos nacionais foi sempre o resultado não apenas de pressões externas, mas também de impulsos endógenos, o efeito da articulação entre alinhamentos de conveniência e amadurecimentos autônomos de posições políticas... ${ }^{5}$

Mais um exemplo que vale lembrar aqui, e que certamente mereceria um aprofundamento, é o da própria formulação da política de revolução em duas etapas. Pensamos que dificilmente poderíamos entender tal formulação como fruto exclusivo do desenvolvimento e das discussões dos grupos nacionais a partir de suas análises das realidades locais sem considerar suas relações com as formulações teóricas da IC. ${ }^{6}$ Nessa formulação, está presente muito da complexidade, a qual estamos nos referindo, da relação entre os partidos comunistas e os centros revolucionários internacionais.

$$
* * *
$$

Sem pretender resolver a complexidade teórica do problema, mas considerando a dimensão que assume dentro dos partidos comunistas a problemática de suas relações com as correntes do comunismo internacional, vamos tentar discutir algumas das relações estabelecidas pelo PC do B com os centros revolucionários na década de sessenta, assim como algumas conseqüências desse relacionamento para a história do partido.

No caso do PC do B, tentaremos demonstrar que suas relações com o mundo comunista foram bem mais complexas do que as usualmente apontadas pelos estudos a seu respeito. A nossa hipótese é a de que o fato de o partido se filiar oficialmente ao maoísmo não significou que as outras experiências revolucionárias deixaram de interferir em sua trajetória. Nesse cami-

5 AGOSTI, A. O mundo da terceira internacional: os estados maiores. In: HOBSBAWM, E. J. (Org.). História do marxismo. Rio de Janeiro: Paz e Terra, 1985. v. 6, p. 166.

6 Uma discussão sobre o conceito de revolução das esquerdas brasileiras pode ser vista em GARCIA, M. A. As esquerdas no Brasil e o conceito de revolução: trajetórias. In: ARAÚJO, A. M. C. (Org.). Trabalho, cultura e cidadania. São Paulo: Scritta, 1997. p. 37-47. 
nho, além do caso da China, a quem o partido defendia publicamente como "exemplo" de caminho revolucionário a ser seguido, vamos discutir também o seu relacionamento com a URSS e Cuba. Entendemos que, para além do discurso oficial de alinhamento ao Partido Comunista Chinês (PCC), o PC do $\mathrm{B}$ teve que manter um diálogo permanente com estes dois últimos países. Mesmo que tenha sido de crítica e recusa, esse diálogo obrigava o partido a se pronunciar a respeito dos vários caminhos que se abriam diante da militância partidária naquela conturbada conjuntura da década de sessenta.

\section{A URSS e o revisionismo}

O PC do B assumiu oficialmente, pouco depois de seu surgimento, um alinhamento com a política externa do PCC e, ideologicamente, com o maoísmo. Ainda assim manteve relações com outras correntes do mundo comunista e, entre elas, com a URSS. Tanto o PC do B quanto as outras esquerdas que se intitulavam comunistas não podiam deixar de se pronunciar a respeito do país onde havia sido edificada a primeira sociedade fruto de uma revolução "proletária" vitoriosa e que havia gozado, pelo menos até 1956, de um prestígio praticamente inquestionável entre os comunistas. No período que aqui discutimos, poderíamos questionar e discordar dos rumos que tomava a "pátria comunista", mas, ainda assim, dificilmente algum estrato das esquerdas comunistas se furtou a se pronunciar a seu respeito.

Antes de falarmos estritamente das relações que o PC do B estabeleceu com a URSS, vale a pena fazer algumas considerações a respeito da dimensão que assumia esse país dentro do mundo comunista, o que, afinal, também influenciou esse relacionamento. Além disso, vale lembrar, o núcleo dirigente do PC do B teve uma formação marcada por uma visão que enxergava na URSS e no PCUS exemplos incontestes a serem seguidos, ${ }^{7} \mathrm{o}$

7 Nesse sentido, podemos lembrar que, até 1956, quando foram denunciados os seus crimes, a figura de Stalin era idolatrada por todos os PCs. Basta dizer que, em 1953, quando o velho ditador morreu, três anos apenas antes do XX Congresso, os comunistas do mundo inteiro choraram a sua morte e no Brasil não foi diferente. A respeito dos aspectos simbólicos na formação dos comunistas brasileiros, ver: FERREIRA, op. cit.; e ALMEIDA, A. W. B. de. As bibliotecas marxistas e as escolas do partido. Religião e sociedade, Rio de Janeiro, n. 9, p. 35-46, jun. 1983. 
que não pode ser desprezado na questão que estamos discutindo. Quanto ao significado da URSS e da Revolução Russa para os comunistas, valem as palavras de Hobsbawm:

Para aqueles cujas memórias políticas não vão além da denúncia de Stalin por Khruschev ou do rompimento sino-soviético, é praticamente impossível imaginar o que a Revolução de Outubro significou para os que são agora ${ }^{8}$ homens maduros. Foi a primeira revolução proletária, o primeiro regime na história a empreender a construção da ordem socialista, prova não só da profundidade das contradições do capitalismo, que provocaram guerras e crises, mas também da possibilidade - da certeza - de que a revolução socialista triunfaria. Foi o começo da revolução mundial, o começo de um mundo novo. Somente os ingênuos acreditavam que a Rússia era paraíso dos trabalhadores, mas mesmo entre os mais avisados, ela gozava de tolerância geral, que a esquerda de 1960 só concede agora a regimes revolucionários de alguns pequenos países, como Cuba e Vietnã... ${ }^{9}$

Um outro ponto levantado pelo autor, e que está intimamente ligado ao primeiro, é o da importância exercida pelo "internacionalismo" na unidade e na atuação dos PCs até a década de cinqüenta:

...Hoje, quando o movimento comunista internacional deixou de existir em grande parte como tal, é difícil imaginar a força imensa que seus membros obtinham da consciência de serem soldados de um único exército internacional que, por mais variado e flexível que fosse em sua tática, executava uma única e ampla estratégia de revolução mundial. Daí a impossibilidade de qualquer conflito fundamental ou duradouro entre o interesse de um movimento nacional e a Internacional, que era o verdadeiro partido e da qual as unidades nacionais não eram mais que seções disciplinadas. Esta força baseava-se tanto em argumentos realistas quanto na convicção moral... ${ }^{10}$

$8 \quad$ O artigo foi escrito em 1969.

9 HOBSBAWM, op. cit., p. 15.

10 Ibid., p. 16. Em relação à força do internacionalismo, vale lembrar o contigente de comunistas do mundo inteiro que foram para a Espanha lutar contra o exército de Franco na Guerra Civil Espanhola. 
Além desses aspectos, do significado da revolução russa para toda uma geração de comunistas e da importância do internacionalismo proletário, há uma outra questão que traria implicações maiores para o relacionamento do $\mathrm{PC}$ do $\mathrm{B}$ com a URSS e que diz respeito ao próprio pragmatismo da política. $\mathrm{O}$ fato desse grupo reivindicar para si, ao surgir, o status de verdadeiro partido comunista em atuação no Brasil - já que o outro, o PCB, ao modificar os seus estatutos, teria, na visão do PC do B, renegado o marxismo-leninismo - trouxe conseqüências para a sua política internacional. Ora, devemos considerar que, para agir com coerência em relação ao seu discurso, o partido deveria, após sua "reorganização" em 1962, se portar exatamente como a continuidade do velho partido comunista fundado em 1922, conforme ele mesmo alegava. E foi nessa condição que o PC do B tentou estabelecer as primeiras relações com o PCUS, tentativa por sinal infrutífera, pois, como veremos, os soviéticos não aceitaram a versão do partido a respeito da cisão e mantiveram relações privilegiadas com o PCB, representado então pela figura de Luís Carlos Prestes.

Com efeito, houve uma tentativa de aproximação e reconhecimento de legitimidade por parte do PC do B em relação à URSS, assim como, simultaneamente, conversações no mesmo sentido com Cuba e China. Em entrevista, um ex-militante do partido, Vicente Roig, ${ }^{11}$ relata como teriam se dado essas tentativas de aproximação. Segundo Roig, Pedro Pomar teria ido para Moscou pedir ao PCUS reconhecimento do PC do B; Lincoln West teria ido a Cuba e João Amazonas teria sido o responsável pelas conversações com o Partido Comunista Chinês. Nas suas palavras:

...a partir daí é que o PC do B se torna, como eles passaram a dizer depois, o primeiro partido no ocidente a romper com o revisionismo e etc., e se torna pró-chinês, e é aí que ele começa a ficar mais claro, percebe? Que, até esse contato com a China, o perfil ainda era muito dúbio, tanto é que eles procuraram a União Soviética, procuraram Cuba, para depois procurarem a China... ${ }^{12}$

11 Vicenti Roig ingressou no PC do B em 1963, saindo do partido no momento da cisão que deu origem ao PC do B Ala Vermelha, no qual então ingressou.

12 ROIG, V. Entrevista concedida a Marcelo Ridenti. Campinas, 30 set. 1985. Está à disposição no Arquivo Edgard Leuenroth (AEL), na Unicamp. 
Não nos interessa aqui os detalhes ou as polêmicas em torno de qual partido o PC do B primeiramente se aproximou, apenas queremos assinalar que, em seus primeiros anos de vida, havia uma certa indefinição de sua parte a respeito dos caminhos a seguir no interior do comunismo internacional e, da mesma forma, do caminho que tomariam suas relações com a URSS. Exemplar nesse sentido é o seu Manifesto-Programa, ${ }^{13}$ no qual o PC do B, na condição de "verdadeiro" partido comunista, trata com cautela as questões internacionais, não faz qualquer menção às divergências no mundo comunista e faz referências elogiosas aos regimes russo, chinês e cubano sem optar por qualquer um deles. A esse respeito, vale darmos uma olhada em uma observação feita pelo próprio partido em 1974, quando da publicação de uma coletânea de documentos sob o título de $A$ linha política revolucionária do partido comunista do Brasil. Tentando explicar o fato de ter elogiado, em 1962, o regime que então passara a ser combatido como um dos grandes inimigos da revolução mundial, lembrou que

O Manifesto-Programa foi elaborado quando não estava ainda suficientemente clara a traição dos revisionistas soviéticos ao socialismo. Por isso, o Manifesto-Programa considera que a União Soviética marcha para o comunismo. Mas, em 1963, o Partido Comunista do Brasil, em sua RESPOSTA A KRUSCHOV, denunciava o caráter antisocialista da política seguida pelos dirigentes da URSS. ${ }^{14}$

A tentativa de aproximação dos soviéticos demonstra também, a nosso ver, que muitos autores erraram ao apontar a origem do PC do B como reflexo no Brasil do cisma sino-soviético. Se fosse esse o caso, o partido teria imediatamente, após a cisão, procurado os chineses. Ao contrário disso, seguindo a tradição da qual seu núcleo dirigente era tributária, representada pela URSS, o partido tentou se aproximar dos soviéticos e até mesmo dos cubanos, sendo que a opção definitiva pela China não se deu antes de 1963.

13 PARTIDO COMUNISTA DO BRASIL. A linha política revolucionária do Partido Comunista do Brasil. Lisboa: Maria da Fonte, 1974. p. 11-24.

14 Ibid., p. 24. Grifo no original. 
As relações do PC do B com o PCUS tomaram contornos mais definidos a partir de fevereiro de 1963, quando o partido - depois de ter visto a sua tentativa de estabelecer relações privilegiadas com os soviéticos naufragar -, rompeu publicamente com a URSS através da publicação em seu jornal de um artigo intitulado "Resposta a Kruschov". Nele, o PC do B respondeu a um artigo publicado no Pravda, jornal do PC soviético, no qual os chineses eram acusados de apoiarem grupos antipartidários em vários países, inclusive no Brasil. O PC do B teria sido, nessa matéria, acusado pelo PCUS de ser um desses grupos antipartidários, divisionistas, que estariam agindo contra os interesses da revolução. $O$ partido rebate as acusações e diz que não aceita “.... conduta daqueles que, na direção do maior país socialista, renegam as gloriosas tradições do bolchevismo e apoiam abertamente os revisionistas em todas as partes do mundo..."15

O PC do B iniciou com esse artigo um tema que passaria a marcar definitivamente sua relação com a Rússia comunista: o combate ao que ele chamava de revisionismo soviético, o maior inimigo da revolução mundial. É possível acompanhar em seus documentos, a partir de então, uma preocupação em se posicionar contra os rumos que o PCUS estaria dando à sociedade soviética, a qual estaria se afastando dos princípios marxistasleninistas.

Do mesmo modo, esse documento também pode exemplificar os parâmetros segundo os quais as críticas passariam a ser feitas. A crítica seria sempre contra a "atual" direção do PCUS, que desviava o partido do rumo traçado por "Lênin e Stalin"; porém, ao mesmo tempo, era afirmada a possibilidade e a esperança de que aquele partido retornasse à sua verdadeira tradição revolucionária, afinal de contas não podiam esquecer que fora ele o primeiro partido a fazer uma revolução socialista vitoriosa. Vejamos um trecho que exemplifica bem esse posicionamento:

Confiamos que o heróico e experimentado Partido do grande Lenin saberá encontrar o melhor caminho para liquidar as

15 PARTIDO COMUNISTA DO BRASIL. Resposta a Khrushcev. A Classe Operária, n. 448, 1-15 ago. 1963. Citaremos a versão publicada em: PARTIDO COMUNISTA DO BRASIL, 1974, op. cit., p. 35 . 
posições errôneas de sua direção, que tantos danos vêm causando à luta revolucionária, estabelecer relações justas com os partidos irmãos e repudiar o revisionismo, desvio mais perigoso no movimento comunista mundial. ${ }^{16}$

Um outro exemplo, no mesmo sentido, podemos encontrar em artigo de uma edição de $A$ Classe Operária, órgão oficial do partido, de dezembro de 1967, em homenagem ao aniversário da revolução russa:

Ao comemorar o $50^{\circ}$ aniversário do grande Outubro, o Comitê Central do Partido Comunista do Brasil vê na grande Revolução de 1917 o mais destacado e glorioso marco da história da humanidade, o caminho a ser trilhado pelos trabalhadores de todas as raças e todos os continentes. Em que pesem a traição dos revisionistas contemporâneos e os revezes temporários da luta revolucionária, O PC do Brasil encara o futuro com plena confiança...

Enfim, como já ressaltamos, o PC do B, ao surgir em 1962, passou por uma fase de indefinição quanto às suas alianças internacionais, chegando a ter conversações com pelo menos três centros revolucionários, e só posteriormente dando destaque preferencial aos contatos com a China. Já nas conversações com a URSS houve uma tentativa de ver legitimada sua condição de "verdadeiro" partido comunista no Brasil. Como não se concretizaram suas expectativas, o partido estabeleceu com esse país uma relação, ao mesmo tempo, de crítica, ao que ele chama de revisionismo, e de respeito pelo partido fundado por Lênin, pois acreditava que ele ainda retomaria seu rumo revolucionário.

Antes de falarmos sobre as relações com a China, que tiveram um papel preponderante no PC do B na década de sessenta, vejamos como o partido reagiu à vitória da revolução e posterior implantação do socialismo em Cuba. Tema que, aliás, receberia larga atenção de sua direção. 


\section{Cuba e o foquismo}

A revolução cubana de 1959 teve grande influência sobre as esquerdas latino-americanas na década de sessenta e parece ter representado um marco nas lutas políticas do continente. Uma vez vitoriosa a revolução, seu "modelo" passou a ser discutido no seio das esquerdas e seus protagonistas, por algum tempo, proclamaram a estratégia revolucionária utilizada em Cuba como válida, pelo menos, para a América Latina.

No Brasil, a vitória de uma revolução nesse pequeno país da América Central causou grandes debates em suas esquerdas. Para alguns autores, esse impacto pode ser visto como um divisor de águas na trajetória política das esquerdas brasileiras, pelo menos no que diz respeito a sua idéia de revolução. Num ambiente de impasse econômico e de rearticulação política, a revolução cubana colocava alguns problemas que, de alguma forma, precisavam ser respondidos por nossas esquerdas. Segundo Garcia, seriam pelo menos três as questões colocadas pela experiência cubana no período: 1 . a do caráter da revolução; 2 . a das possibilidades do caminho pacífico; 3 . a do tipo de vanguarda necessária para se fazer uma revolução. ${ }^{17}$

Para Emir Sader, podemos dizer que havia, no período que vai de 1959 até início dos anos setenta, duas leituras sobre o triunfo revolucionário cubano. Uma, "suave", feita pelo PCB e pelos nacionalistas em geral, na qual eram ressaltadas as rupturas com imperialismo e sua plataforma nacional, democrática e popular. Outra leitura, feita pela esquerda revolucionária, enfatizava o caráter socialista assumido pelos cubanos e a utilização da violência revolucionária para a tomada do poder. ${ }^{18}$

As relações do PC do B com a revolução cubana, assim como ocorreu com o restante das esquerdas no período, foram bastante complexas. Sobre elas incidiam tanto fatores internos do processo revolucionário cubano quanto fatores da conjuntura brasileira. Além, é claro, dos debates envolvendo a China e a URSS, que então passavam a ser travados publica-

17 Ver: GARCIA, M. A. Surge a nova esquerda. Em Tempo, São Paulo, n. 79, ago./set. 1979; e GARCIA, M. A. Como surge a esquerda armada brasileira. Em Tempo, São Paulo, n. 81, 13-19 set. 1979.

18 SADER, E. Cuba no Brasil: influências da revolução cubana na esquerda brasileira. In: REIS FILHO, D. A. et al. História do marxismo no Brasil. Rio de Janeiro: Paz e Terra, 1991. v. 1, p. 176. 
mente, polarizando discussões em torno da problemática do alinhamento internacional por parte das esquerdas comunistas. Nesse sentido, para Emir Sader, a defesa da via chinesa viria, no caso do PC do B, junto com uma crítica ao regime cubano, que teria, segundo o partido, tornado-se um reforço aos revisionistas russos. ${ }^{19}$

Ainda que esse aspecto apontado por Sader seja, sem dúvida, uma das marcas distintivas do relacionamento do partido com a revolução cubana, acreditamos haver outros elementos em jogo que merecem ser considerados. Sem querer resumir aqui a essência dessas relações, para efeito de análise, podemos apontar dois momentos que se destacam nesse relacionamento. Um se iniciaria em 1962, quando a revolução era tida pelo PC do B como um exemplo para o continente latino-americano e para o Brasil em particular; e um outro a partir de 1966, no qual o partido assumiu publicamente uma postura crítica em relação às aspirações de Cuba de se tornar catalisadora de uma possível revolução continental.

A questão da possibilidade de fazer no continente uma revolução armada e socialista é importante, entre outras coisas, por ter sido um ponto essencial nos debates da esquerda revolucionária, o que obrigava o PC do $\mathrm{B}$ a responder, pelo menos a seus militantes e simpatizantes, porque a estratégia utilizada em Cuba não se adequaria ao Brasil. Ou seja, a força do exemplo cubano no seio da esquerda revolucionária brasileira levava o partido a se pronunciar a respeito da via cubana, sob o risco de ver seus militantes arrastados pela onda militarista que tomava conta dos agrupamentos comunistas brasileiros, em boa parte sob a influência do foquismo.

Quanto ao primeiro momento da relação do PC do B com a revolução cubana, caracterizado pelo apoio aos cubanos e da tomada dessa experiência revolucionária como exemplo para o Brasil e para a América Latina, ele pode ser facilmente exemplificado através da observação das páginas do periódico oficial do PC do B, A Classe Operária, no qual, em praticamente todas as edições entre 1962 e 1964, há referências simpáticas a Cuba. Seja através de artigos dos dirigentes do partido, seja por publicações assinadas pelo próprio Fidel Castro e Che Guevara, o apoio à revolução cubana estava estampado nas páginas de seu jornal. 
No entanto, o apoio praticamente irrestrito à revolução cubana não duraria muito. Em março de 1966, através de um documento intitulado "O marxismo-leninismo triunfará na América Latina (carta aberta a Fidel Castro)", ${ }^{20}$ a direção do PC do B criticou publicamente os rumos tomados por Cuba. Teve início aí um segundo momento nas relações do partido com o regime cubano.

As duas questões que levariam o PC do B a modificar suas atitudes em relação à revolução cubana aparecem claramente no documento acima. A primeira seria a tentativa dos revolucionários da ilha de irradiar seu modelo revolucionário para a América Latina, no momento em que, no Brasil, surgiam diversos agrupamentos de esquerda procurando uma alternativa para a política até então adotada pelo PCB, responsabilizada pela derrota em abril de 1964. Para esses grupos, a experiência cubana era um exemplo a ser seguido, uma vez que teria mostrado a possibilidade de se fazer uma revolução socialista através da luta armada a poucas milhas dos EUA. Agora já não eram os partidos comunistas a utilizar a revolução cubana como exemplo de revolução democrática, para assim respaldarem sua política; ao contrário, os cubanos passavam a criticar a estratégia e a burocratização dos Partidos Comunistas (PCs) latino-americanos e propunham e estimulavam, inclusive materialmente, o caminho do foco, que, se seguido, levaria à implosão do próprio modelo clássico de partido comunista. Essa política de exportação do foquismo, vale dizer, causou divergências não só com $\mathrm{PC}$ do $\mathrm{B}$, mas com praticamente todos os PCs pró-Moscou do continente. ${ }^{21}$

Com efeito, a tentativa de expansão do modelo revolucionário cubano se afigurava como a maior divergência em relação à revolução de Fidel Castro. A partir desse momento, ao PC do B não bastava a escolha do maoísmo, tornara-se necessário esclarecer aos seus militantes os "perigos" e os "erros" que envolveriam o foquismo e o fidelismo. Nesse sentido, advertia o partido:

20 Cf. PARTIDO COMUNISTA DO BRASIL, 1974, op. cit., p. 85-100.

21 BANDEIRA, L. A. M. De Martí a Fidel. A revolução cubana e a América Latina. Rio de Janeiro: Civilização Brasileira, 1998. p. 305. Um exemplo da ligação orgânica do regime cubano com setores da esquerda revolucionária brasileira pode ser visto no trabalho de CRUZ, D. R. O apoio de Cuba à luta armada no Brasil: o treinamento guerrilheiro. Rio de Janeiro: Mauad, 2001. 
...toda tentativa de aplicar, dogmaticamente em outro países, o que há de específico naquela revolução só poderá redundar em fracasso. Ainda que o exemplo de Cuba, em especial no que se refere ao princípio geral da luta armada, continue a inspirar os que lutam pela liberdade e contra o imperialismo norteamericano, o fidelismo não vem dando frutos neste continente, não foi comprovado em nenhum outro país... ${ }^{22}$

A partir de então, nos documentos do partido, haveria sempre um espaço para críticas ao modelo cubano, as quais pareciam aumentar em quantidade e intensidade à medida que aumentava a pressão no interior do PC do B por uma adesão efetiva à luta armada. ${ }^{23}$ Nesse sentido, por exemplo, o partido dedicaria, em um documento de novembro de $1967,{ }^{24}$ nove páginas às críticas ao "fidelismo".

A segunda questão que incomodava o partido era a aproximação de Fidel Castro da política externa soviética. Esse problema deve ser entendido dentro das disputas travadas entre o PCUS e PCC pela hegemonia do movimento comunista internacional, sendo que, no caso cubano, a opção se deu, gradativamente, pelo campo de influência soviético. Esse fato levou o PC do B, então aliado da China, a criticar os cubanos e a colocar Fidel no campo do "revisionismo contemporâneo". Nesse sentido, para o partido, Castro adotara

...a política capitulacionista e de traição dos dirigentes do PCUS, com os quais se mostra cada vez mais afinado. Embora você (Fidel Castro) procure aparentar independência, fica evidente para os trabalhadores e os revolucionários da América Latina que você atua como peça do mecanismo montado por Krushov e aperfeiçoado pelos seus sucessores... ${ }^{25}$

22 O PARTIDO COMUNISTA DO BRASIL, 1974, op. cit., p. 91-92.

23 Essa questão da tensão no interior do partido entre uma linha voltada para o trabalho com as massas e outra voltada para a luta armada é discutida por POMAR, W. Araguaia. O partido e a guerrilha. São Paulo: Brasil Debates, 1980.

24 O PARTIDO Comunista do Brasil na luta contra a ditadura militar. In: PARTIDO COMUNISTA DO BRASIL. Guerra popular. Caminho da luta armada no Brasil. Lisboa: Maria da Fonte, 1974. p. 23-70.

25 O PARTIDO COMUNISTA DO BRASIL, 1974, op. cit., p. 98. 
Essas críticas dirigidas a Cuba não impediam que o documento fosse finalizado com um "apelo fraternal", como ocorreu nas críticas ao PCUS, e com a esperança de que Fidel voltasse às fileiras revolucionárias. No entanto, o PC do B não poderia esperar tranqüilamente essa volta, pois a questão da luta armada tornara-se, na segunda metade da década de sessenta, um divisor de águas, que indicava quem estava no campo do reformismo ou da revolução. O partido não poderia se esquivar diante de tal problema e a experiência chinesa aparecia naquele momento como uma saída que, por um lado, propunha a luta armada, mas, por outro, diferente do foquismo cubano, não abria mão da organização partidária como elemento fundamental na condução do processo revolucionário.

\section{Maoísmo, ortodoxia e revolução cultural}

No que tange às relações do $\mathrm{PC}$ do $\mathrm{B}$ com o comunismo chinês, podemos começar ressaltando uma questão que seria fundamental na opção do partido pelo alinhamento ao PCC: as diferenças do maoísmo em relação ao foquismo. Se os dois tinham pontos em comum, como o privilégio dado ao campesinato e à guerrilha rural, a ênfase nos povos do Terceiro Mundo e o teor militarista de suas estratégias revolucionárias, o primeiro tinha aspectos próprios que o tornava muito mais atraente para um partido como o PC do B, tributário da tradição comunista da III IC. Como assinala Gorender, havia aí duas diferenças fundamentais:

...Em primeiro lugar, (o maoísmo) subordinou o fator militar
ao fator político. O exército guerrilheiro devia estar sob direção
absoluta do partido comunista. O partido precede a guerrilha e
esta não surge e se desenvolve senão mediante o trabalho
político entre os camponeses. A perspectiva devia ser, por isso,
a da guerra popular prolongada. Em segundo lugar, a liderança
chinesa não endossou o objetivo socialista imediato, salientado
nos escritos de Guevara, porém continuou a defender a
concepção da revolução em duas etapas. Bem como a tese da 
aliança com a burguesia nacional na etapa da revolução antiimperialista e antifeudal. ${ }^{26}$

Vale a pena também assinalar que a via chinesa vem se apresentar de forma clara, como modelo e alternativa em relação a outras estratégias revolucionárias, somente por volta de 1963, quando ocorreu o rompimento público entre o Partido Comunista Chinês e o PCUS. Nesse sentido, segundo Reis Filho,

...é exatamente a partir desse conflito, e das dimensões que adquire, que o maoísmo surge na cena internacional com um perfil nítido enquanto alternativa para o conjunto do movimento comunista. Em outras palavras: o maoísmo não se gesta a partir do ou concomitante ao cisma sino-soviético, mas é inegável que o cisma contribui decisivamente para descobri-lo ou revelá$l o$, atuando como um catalisador, precipitando contradições latentes e acelerando sua dramática eclosão. ${ }^{27}$

Nesse caminho, é preciso entender o relacionamento do PC do B com o PCC considerando os aspectos internacionais que estão envolvidos, como a cisão no mundo comunista, e os aspectos nacionais, como a situação e inserção do PC do B na conjuntura brasileira, para perceber que entre os comunistas chineses e brasileiros havia interesses comuns que os levaram a se tornarem aliados políticos. O PCC disputava com o PCUS a hegemonia no movimento comunista internacional, o que tornava interessante uma aliança com um partido comunista no Brasil, o qual, ainda por cima, disputava espaço político com um grupo pró-Moscou. O PC do B, por sua vez, encontrava no maoísmo embasamento para dar respostas, principalmente quanto à questão da luta armada, àquela conturbada conjuntura que se abriu após o golpe militar de 1964, quando a adesão à luta armada se tornou um divisor de águas entre "reformistas" e "revolucionários" para

26 GORENDER, J. Combate nas trevas. 5. ed. São Paulo: Ática, 1998. p. 91.

27 REIS FILHO, D. A. O maoísmo e a trajetória dos marxistas brasileiros. In: REIS FILHO et al., 1991, op. cit., p. 118 . 
boa parte das esquerdas brasileiras. Com a adesão ao maoísmo, o partido pôde aderir a um projeto de luta armada sem, entretanto, ter que partir para o embate imediato com a ditadura, como fizera a maior parte da esquerda revolucionária brasileira.

Antes de continuar discutindo a relação propriamente do PC do B com o maoísmo, vale a pena falarmos um pouco do restante das esquerdas, principalmente da chamada esquerda revolucionária, para lembrar que, longe de aparecer para elas como uma doutrina exótica, o maoísmo vinha ao encontro de muitas de suas aspirações e, se o PC do B aderiu oficialmente à China, isso não impediu que outros grupos se apropriassem de muitos aspectos do maoísmo, ainda que lhe fazendo restrições.

O PCB, isolado e em processo de sangria no pós-64, segundo Reis Filho, via o maoísmo como uma "febre infantil" no movimento comunista internacional e previa que a revolução chinesa voltaria logo aos eixos verdadeiramente revolucionários e a harmonia voltaria a reinar no campo socialista. $^{28}$

O restante das esquerdas se dividiam na apreciação do maoísmo. Havia um grupo formado pelos partidários da estratégia "socialista/ insurreicional/operária", cujo núcleo era a ORM-POLOP, que via no maoísmo uma referência na luta contra o "revisionismo soviético" e o apreciava pela crítica ao processo de burocratização do socialismo. ${ }^{29}$ É claro que também havia críticas ao maoísmo. À ORM-POLOP, por exemplo, incomodava o "culto à personalidade" de Mao e a defesa da figura de Stalin patrocinada pelos chineses.

Um outro grupo reunia as dissidências do PCB, as cisões da ORMPOLOP e mais a ALN e o PCBR. Esses grupos, que valorizavam suas afinidades com a experiência cubana de uma forma mais clara, apreciavam no maoísmo

...a revolução violenta, a perspectiva de organização de uma força armada própria, a ênfase na aliança operário-camponesa

28 REIS FILHO et al., 1991, op. cit., p. 127.

29 Ibid., p.128. 
em detrimento de compromissos com as burguesias locais. Por outro lado, certas organizações, como a Ação Libertadora Nacional (ALN), e o Partido Comunista Brasileiro Revolucionário (PCBR) e os Comandos de Libertação Nacional (COLINA), que mantinham definições a longo prazo favoráveis à formação de amplas frentes populares, incluindo até mesmo estratos das burguesias locais, encontravam conforto nas teses maoístas que, sem abdicar da luta armada, conservaram esse tipo de perspectiva de revolução até a vitória da revolução em 1949. Estas mesmas definições, inversamente, eram rejeitadas pelas dissidências do $\mathrm{PCB}$, que se inclinariam pela estratégia socialista. ${ }^{30}$

Ainda devemos lembrar o caso da Ação Popular (AP), que surge em 1962 e que, em sua trajetória, vai de um "catolicismo social revolucionário" ao maoísmo. Finalmente, temos o grupo formado pelo PC do B e suas cisões (Partido Comunista do Brasil - Ala Vermelha e Partido Comunista Revolucionário), que reivindicariam oficialmente o maoísmo como exemplo revolucionário, ainda que, principalmente no caso de suas cisões, mesclado com muitos aspectos do foquismo.

Como podemos ver, o maoísmo exerceu, em grau diferenciado, certa atração em boa parte das esquerdas brasileiras na década de sessenta. Vale apontar, e caberia um estudo mais aprofundado sobre a questão, que essa doutrina conseguiu adeptos em muitos países da América Latina e que, em alguns lugares, o processo ocorreu de uma forma parecida com o caso do PC do B. Isto é, a partir de problemas dentro de um partido comunista tradicional, pró-Moscou, há uma cisão que dá origem a outro partido que adota oficialmente as idéias chinesas. Em um dos casos, inclusive, chama a atenção a convivência, durante algum tempo, de idéias castristras e guevaristas com o ideário maoísta, convivência esta que também caracterizou o partido brasileiro em seus primeiros anos. Trata-se do caso do Partido Comunista (Marxista-Leninista) da Colômbia, que em um documento de 1965 nos dá um exemplo lapidar dessa convivência: “...a guerra popular 
não pode progredir sem ofensiva tática, ou, como diz Che Guevara, sem defesa com ataque." 31

Além da Colômbia, surgiram grupos pró-chineses em vários países. Os mais importantes nasceram no Peru, em 1964, e na Bolívia, em 1965. Apareceram também no Equador, no Chile, na República Dominicana, Argentina e México. ${ }^{32}$

Ainda em relação ao maoísmo e aos motivos que fizeram com que tantas organizações se sentissem atraídas pelo seu ideário, devemos lembrar que ele não foi um corpo imutável de idéias; ao contrário, é possível perceber claras mudanças em suas formulações entre o seu surgimento até o final da década de sessenta. Podemos apontar pelo menos três momentos importantes no desenvolvimento do maoísmo enquanto teoria revolucionária. Talvez essas modificações do maoísmo no decorrer da década de sessenta possam nos ajudar a entender porque ele conseguiu influenciar grupos políticos de variados matizes dentro das esquerdas.

Um primeiro momento do maoísmo, com a vitória da revolução chinesa, foi marcado pela contribuição de Mao Tse-tung ao corpo doutrinário do marxismo-leninismo com a sua estratégia do bloco de quatro classes. Como sugere um autor, ao mesmo tempo em que despertaria interesse na América Latina, já que tal revolução tinha sido feita em um país "periférico", em condições muito mais próximas do continente americano, o maoísmo se adequaria perfeitamente à ortodoxia stalinista da revolução em etapas e, do mesmo modo, à política de frente popular. ${ }^{33}$

Uma segunda fase poderia ser apontada a partir do conflito sinosoviético, passando pelos ataques a Khrushchev e pelo rompimento público com os russos, a qual se caracterizaria por uma defesa da ortodoxia e da figura de Stalin frente às mudanças implementadas pelos dirigentes soviéticos após o XX Congresso do PCUS.

31 Esse partido surgiu como cisão do partido comunista da Colômbia em 1963. Na década de sessenta, empreendeu a luta armada através da criação, em 1967, do Exército de Libertação do Povo. Nos anos setenta viria a se enfraquecer por causa de sucessivas cisões. Ver: LÖWY, M. O marxismo na América Latina. Uma antologia de 1909 aos dias atuais. São Paulo: Fundação Perseu Abramo, 1999. p. 437.

32 A esse respeito, ver: JOHNSON, C. Communist Chine and Latin America. New York: Columbia University Press, 1970.

33 GARCIA, M. A. Le parti communiste chilien et les alliances de classes. Critiques de L'économie Politique, Paris, n. 27, p. 41-61, avr./juin 1977. 
Um terceiro momento do pensamento de Mao Tse-tung pode ser visto a partir da revolução cultural proletária e seria caracterizado pelo rompimento com muitos dogmas da organização nos moldes dos partidos comunistas e por uma crítica às estruturas de funcionamento da sociedade comunista chinesa.

Nesse caminho, acreditamos que o PC do B aderiu ao maoísmo pelas orientações de sua primeira e segunda fase, fundamentalmente no que diz respeito à defesa da ortodoxia stalinista. Basta lembrar que o grupo que fundou o PC do B foi crítico ferrenho das mudanças implementadas após o $\mathrm{XX}$ Congresso e que, ainda por cima, viu suas pretensões de estabelecerem relações privilegiadas com os russos serem recusadas pelo PCUS, que continuou se relacionando com o grupo de Prestes. Como vimos, esse episódio fez o PC do B se tornar um crítico fervoroso da nova orientação soviética ao mesmo tempo em que estreitava seu laços com os chineses.

Essa idéia de que o PC do B se aproximou do maoísmo via defesa da ortodoxia stalinista pode também ser percebida, por contraste, ao observarmos que os grupos da chamada esquerda revolucionária - críticos de muitos aspectos dessa ortodoxia - se aproximaram dos chineses muito mais pelas idéias da revolução cultural e não nutriam qualquer simpatia pelo PC do B. Exemplares nesse sentido seriam as próprias cisões sofridas pelo partido que, apesar de grande influência do foquismo, tiveram na revolução cultural um importante referencial político. Do mesmo modo, mesmo a $\mathrm{AP}$, que se aproximou dos chineses e viria a se incorporar ao PC do B, chegou ao maoísmo por um caminho distinto do seguido por este último. Para Marcelo Ridenti,

...a aproximação do PC do B com o maoísmo veio de uma identidade histórica comum, ancorada no marxismo-leninismostalinismo, que pouco tem de romântico. Ao passo que a prevalência do maoísmo na AP ligou-se essencialmente à afinidade romântica dessa organização com a revolução cultural proletária. De resto, AP e PC do B, durante os anos 60, sempre se antagonizaram na disputa pela vanguarda da revolução brasileira... ${ }^{34}$

34 RIDENTI, M. S. Em busca do povo brasileiro: romantismo revolucionário de artistas e intelectuais (pós-60). Campinas, 1999. Tese (Livre-Docência) - Universidade de Campinas. p. 155. 
A chegada ao maoísmo via defesa da ortodoxia stalinista dava suporte para que o partido estabelecesse uma estratégia revolucionária em que, necessariamente, deveria estar presente o horizonte da luta armada, mas sem ter que partir para ações imediatas, como fizeram muitos grupos no período. Se, em 1962, o partido pôde surgir levantando retoricamente a bandeira da luta armada, na conjuntura do pós-64, a prática, entendida como ações efetivas e armadas contra a ditadura, tornara-se o divisor de águas do verdadeiro revolucionário em relação ao "pacifismo" e "reformismo" do PCB. Não aderir à luta armada poderia significar, naquela conjuntura, perda de militantes para outras organizações que tinham saído na frente e empreendido as primeira ações contra a ditadura militar.

O PC do B, entretanto, precisava enfrentar essa questão sem abrir mão da estrutura partidária, uma vez que, naquele momento, como vimos acima, as idéias cubanas, que abriam mão dessa estrutura, gozavam de grande respaldo no seio das esquerdas e muitos grupos já surgiam mesmo em oposição à estrutura tradicional identificada com a imagem do partido comunista de inspiração leninista. O maoísmo possibilitava colocar-se no campo dos que defendiam a luta armada sem, entretanto, abrir mão de sua estrutura organizativa. Entre outras coisas, isso significou para o partido poder responder a seus militantes em relação ao problema da luta armada, enquanto fazia os preparativos para sua guerra popular prolongada, sem ter que partir para ações efetivas nas cidades, uma vez que o maoísmo privilegiava o campo como cenário da luta revolucionária. Dessa forma, o PC do B pôde preservar sua estrutura organizacional, enquanto o restante das esquerdas se debatia e era destruído nas cidades por uma repressão cada vez mais fortalecida e organizada.

Como podemos observar, longe de ser casual, a opção pelo regime chinês e a aproximação do maoísmo estão fundamentadas, ao mesmo tempo, em opções teóricas - defesa da ortodoxia stalinista, teoria do bloco das quatro classes, revolução por etapas e a idéia de guerra popular prolongada - e na prática política - recusa do PCUS em lhe oferecer relações políticas privilegiadas e necessidade de uma estratégia de luta armada para se contrapor à atração exercida pelo ideário guevarista.

Ao mesmo tempo em que o maoísmo desempenhava um papel crescente nas fileiras partidárias, também ganhava destaque no jornal e nos documentos assinados pela direção do PC do B. No jornal A Classe Operária, havia sempre um grande espaço reservado para noticiar acontecimen- 
tos relacionados à China. Seja através de artigos elogiosos, publicações de documentos ou notícias sobre a polêmica com o PCUS, a questão chinesa sempre era tratada em relevo pelo jornal. Só para termos uma idéia do espaço reservado a notícias relacionadas à China, em uma edição de junho de 1969, das dez páginas do jornal, cinco foram usadas para divulgação do IX Congresso do PCC.

Entretanto, é nos documentos produzidos pela direção do partido que podemos ver melhor a presença do maoísmo nas formulações do PC do B. No documento aprovado na sua VI Conferência, em 1966, podemos perceber a opção pela fórmula maoísta da guerra popular prolongada como estratégia revolucionária, ${ }^{35}$ uma vez que, como vimos, em seu ManifestoPrograma, o partido ainda não tinha se definido sobre suas relações com o mundo comunista. Cabe lembrar, no entanto, que, mesmo nesse documento elaborado em sua VI Conferência, a opção pela guerra popular não se dá de forma acabada, uma vez que vem junto com uma proposta de união nacional em torno de uma frente política, buscando a redemocratização do país. Para Gorender, essas táticas seriam diametralmente opostas e estariam justapostas no documento. ${ }^{36}$ Para Wladimir Pomar, a dualidade do documento não era casual e sim fruto das dúvidas e divergências dentro do partido em relação à questão da luta armada. ${ }^{37}$ De qualquer forma, as fórmulas maoístas estão presentes no documento, ainda que, como indica Gorender, não de forma acabada e, como indica Pomar, não tivessem em torno de si a unanimidade dos membros partidários. Nas palavras do partido, a guerra popular seria

...a maneira atual de enfrentar e derrotar os opressores. Não é o caminho clássico de greve geral política e de insurreição nas cidades, tal como ocorreu na antiga Rússia, mas o da luta armada que, paulatinamente, vai-se estendendo até abarcar a esmagadora maioria do povo. No curso da guerra popular, as greves gerais e os levantes nos grandes centros poderão surgir.

35 União dos brasileiros para livrar o país da crise, da ditadura e da ameaça neocolonialista. In: PARTIDO COMUNISTA DO BRASIL, 1974, op. cit., p. 101-175.

36 GORENDER, op. cit., p. 117-118.

37 POMAR, op. cit. 
Não constituirão, no entanto, a sua característica dominante. As forças populares, inicialmente débeis, crescem e tornam-se fortes e superiores às do adversário. Por mais dificuldades que defrontem, por mais derrotas parciais que sofram, sua tendência será a de se ampliar, fortalecer e vencer o inimigo. Sendo parte integrante do povo, têm nele a fonte de sua invencibilidade. ${ }^{38}$

É interessante notar que, junto com a opção pelo maoísmo, há uma crítica ao modelo cubano no que tange a questão da necessidade do partido de conduzir o processo revolucionário. Como dissemos acima, não bastava ao partido a opção pelo modelo maoísta, era necessário indicar as insuficiências do foquismo enquanto estratégia revolucionária. Para o PC do B, as condições em Cuba, que permitiram uma revolução sem partido, não se repetiriam facilmente em outras partes do mundo. Segundo o partido,

...a experiência tem mostrado que não se pode prescindir de um partido revolucionário e que seja marxista-leninista. Toda tentativa de se levar adiante a revolução sem um partido desse tipo fracassou. Os defensores daquela idéia apoiam-se no que ocorreu em Cuba, onde à frente da revolução não se encontrava uma vanguarda marxista-leninista. Mas o que sucedeu naquele país não se repetirá facilmente. Os imperialistas e a reação tomam medidas objetivando a impedir que surja na América Latina processo semelhante ao de Cuba. ${ }^{39}$

O modelo de guerra popular prolongada se cristaliza de forma definitiva nas formulações do PC do B a partir, principalmente, da publicação, em 1969, do documento intitulado Guerra popular - caminho da luta armada no Brasil. ${ }^{40}$ Para Gorender, essa resolução rompia com o "dualismo estratégico", presente no documento da VI Conferência, na medida em que deixava de lado as preocupações com a redemocratização do país através da tática de frente popular e se dedica exclusivamente à luta armada. ${ }^{41}$

38 PARTIDO COMUNISTA DO BRASIL, 1974, op. cit., p. 137.

39 Ibid., p. 148.

40 PARTIDO COMUNISTA DO BRASIL. Guerra popular - caminho da luta armada no Brasil. Lisboa: Maria da Fonte, 1974a, p. 115-160.

41 GORENDER, op. cit., p. 118. 
Para o partido, a Guerra Popular teria no Brasil os seguintes aspectos básicos:

...será uma guerra de cunho popular, travar-se-á fundamentalmente no interior e mobilizará as grandes massas camponesas, será prolongada, deverá apoiar-se em recursos do próprio país, empregará o método da guerrilha em grande escala, forjará o exército popular, estabelecerá bases de apoio no campo. Terá que se orientar, durante muito tempo, pelos princípios da defensiva estratégica e deverá guiar-se por uma política correta. $^{42}$

Talvez, considerando a dificuldade de colocar em prática uma tática dessa grandeza em uma situação de fechamento do regime militar - um mês antes havia sido publicado o Ato Institucional $n^{\circ} 5$, que dava plenos poderes ao regime instituído em 1964 -, o partido encerrou a parte do documento dedicada ao caminho da luta armada com uma otimista citação de Mao Tse-tung:

A revolução e as guerras revolucionárias vão do nascimento ao desenvolvimento, do pequeno ao grande, da ausência de poder à tomada do poder, da ausência de Exército vermelho à criação do Exército vermelho, da ausência de bases revolucionárias à criação das bases revolucionárias. ${ }^{43}$

O relacionamento do $\mathrm{PC}$ do $\mathrm{B}$ com o maoísmo foi intenso até a segunda metade da década de setenta, quando houve um rompimento público do partido com o PCC, e foi feita, então, à moda comunista, uma crítica retrospectiva ao modelo chinês, a qual procurava mostrar que o partido já demonstrava discordância com esse modelo pelo menos desde 1963. De qualquer forma, essa crítica retrospectiva não pôde apagar o fato de que, na década de sessenta, o maoísmo exerceu considerável influência no 
PC do B e foi baseando-se nele que o partido orientou grande parte de sua estratégia política no período.

Quanto ao resultado dessa relação para o PC do B, podemos dizer que ela marcou profundamente, e em vários sentidos, a sua experiência partidária na década de sessenta. Pelo menos dois aspectos dessa relação podem ser ressaltados. Em primeiro lugar, ela possibilitou ao grupo que fundou o PC do B enfrentar a difícil tarefa de organizar um partido comunista em um momento em que a sua matriz, o PCB, atravessava um dos momentos de maior prestígio político, no qual sua estratégia revolucionária parecia ser referendada pelas reformas de base de Goulart e pela presença, na cena política brasileira, de uma ampla frente nacional e antiimperialista.

Em segundo lugar, vale destacar a eficácia do maoísmo junto à sua militância enquanto teoria embasadora de sua estratégia revolucionária. Em que pesem as cisões sofridas pelo partido no período - em grande medida influenciadas pelo foquismo -, a opção pela estratégia de guerra popular prolongada conseguiu agregar em torno de si a maioria dos seus militantes, que conseguiram ficar imunes à sanha militarista que tomou conta da esquerda revolucionária no período. Enquanto isso, graças ao embasamento teórico do maoísmo, o partido fazia os preparativos para sua guerra popular, que desembocaria na experiência da guerrilha do Araguaia. ${ }^{44}$

$$
* * *
$$

Como pudemos observar, as relações internacionais do PC do B com o mundo comunista na década de sessenta foram bem mais complexas do que as usualmente apontadas nos estudos sobre esse partido. Em geral, o que aparece nos trabalhos é uma interpretação muito parecida com a leitura que o próprio partido fazia na década de sessenta sobre a questão. Ou seja, o PC do B, ao surgir, teria optado imediatamente pelo maoísmo por este representar, naquele momento, uma crítica ao revisionismo soviético e uma continuidade, através da teoria da guerra popular prolongada, da tradição

44 Entrevistamos alguns militantes e ex-militantes sobre a história do partido nos anos 60. Todos ressaltaram a importância que o maoísmo exerceu como força aglutinadora e de formação teórica. Ver as entrevista com Sérgio Miranda, Ozeas Duarte, José Renato Rabelo e Celso Nespoli Antunes, que estão à disposição no AEL. 
revolucionária comunista, que teria sido abandonada pelo PCUS e, no Brasil, pelo PCB.

Não é que esta interpretação sobre a relação do PC do B com o maoísmo não tenha fundamento, certamente o tem. Entretanto, a dimensão internacional da política do partido não pode ser reduzida nem a essa fórmula, nem apenas a suas relações com a China, sob pena de se deixar de lado muitos aspectos importantes da sua interação com o comunismo internacional, como alguns dos que esperamos ter indicado acima. Questões como a tentativa de aproximação do PCUS; o debate que o partido foi obrigado a fazer a respeito do foquismo durante toda a segunda metade da década de sessenta; a pressão que a idéia da guerra de guerrilhas exerceu sobre a militância do PC do B, entre outras, não podem ser deixadas de lado. Ainda que não coincidam com a interpretação que o próprio partido faz hoje de sua história naquele período, essas questões estão presentes nos documentos produzidos pelo partido na época e merecem ser discutidas.

Em suma, longe de querer resolver toda a complexidade do problema, acreditamos que dificilmente a trajetória do partido poderá ser entendida sem a discussão adequada dessas questões. Este artigo pretendeu chamar a atenção dos estudiosos para essa espinhosa problemática do relacionamento dos partidos comunistas, em geral, e do PC do B, em particular, com os centros revolucionários internacionais.

\section{Referências}

ALMEIDA, A. W. B. de. As bibliotecas marxistas e as escolas do partido. Religião e Sociedade, Rio de Janeiro, n. 9, p. 35-46, jun. 1983.

ARAÚJO, A. M. C. (Org.). Trabalho, cultura e cidadania. São Paulo: Scritta, 1977.

BANDEIRA, L. A. M. De Martí a Fidel. A revolução cubana e a América Latina. Rio de Janeiro: Civilização Brasileira, 1998.

CARONE, E. $O P C B$ - 1922-1972. Rio de Janeiro: Bertrand, 1973.

CHILCOTE, R. O Partido Comunista Brasileiro: conflito e integração, 1922-1972. Rio de Janeiro: Graal, 1982. 
CRUZ, D. R. O apoio de Cuba à luta armada no Brasil: o treinamento guerrilheiro. Rio de Janeiro, [s. n.], 2001.

FERREIRA, J. L. Prisioneiros do mito: cultura e imaginário político dos comunistas no Brasil - 1930-1956. São Paulo, 1996. Tese (Doutorado) - Universidade de São Paulo.

GARCIA, M. A. Como surge a esquerda armada brasileira. Em Tempo, São Paulo, n. 81, p. 13-19, set. 1979.

GARCIA, M. A. Le Parti Communiste Chilien et les alliances de classes. Critiques de L'économie Politique, Paris, n. 27, p. 41-61, avr./juin 1977.

GARCIA, M. A. Surge a nova esquerda. Em Tempo, São Paulo, n. 79, ago. 1979.

GORENDER, J. Combate nas trevas. 5. ed. São Paulo: Ática, 1998.

HOBSBAWM, E. J. (Org.). História do marxismo. Rio de Janeiro: Paz e Terra, 1985.

HOBSBAWM, E. J. Revolucionários. Ensaios contemporâneos. Rio de Janeiro: Paz e Terra, 1982.

JOHNSON, C. Communist Chine and Latin America. New York: Columbia University Press, 1970.

LÖWY, M. O marxismo na América Latina. Uma antologia de 1909 aos dias atuais. São Paulo: Fundação Perseu Abramo, 1999.

PACHECO, E. O Partido Comunista no Brasil, 1922-1964. São Paulo: Alfa-Ômega, 1984.

PARTIDO COMUNISTA DO BRASIL. A linha política revolucionária do Partido Comunista do Brasil. Lisboa: Maria da Fonte, 1974.

PARTIDO COMUNISTA DO BRASIL. Guerra popular. Caminho da luta armada no Brasil. Lisboa: Maria da Fonte, 1974a.

POMAR, W. Araguaia. O partido e a guerrilha. São Paulo: Brasil Debates, 1980.

REIS FILHO, D. A. A revolução faltou ao encontro. Os comunistas no Brasil. 2. ed. São Paulo: Brasiliense, 1990.

REIS FILHO, D. A. et al. História do marxismo no Brasil. Rio de Janeiro: Paz e Terra, 1991.

RIDENTI, M. S. Em busca do povo brasileiro: romantismo revolucionário de artistas e intelectuais (pós-60). Campinas, 1999. Tese (Livre-Docência) - Universidade de Campinas. 
ROIG, V. Entrevista concedida a Marcelo Ridenti. Campinas, 30 set. 1985.

SALES, J. R. Partido Comunista do Brasil - PC do B: propostas teóricas e prática política (1962-1974). Campinas, 2000. Dissertação (Mestrado) - Universidade de Campinas.

SANTOS, R. A primeira renovação pecebista: reflexos do XX Congresso do PCUS no PCB. Belo Horizonte: Oficina de Livros, 1988.

VINHAS, M. O partidão: a luta por um partido de massas, 1922-1944. Rio de Janeiro: Graal, 1982. 